\title{
Primary hypogammaglobulinemia: The impact of early diagnosis in lung complications
}

\author{
Mayra de Barros Dorna ${ }^{1 *}$, Cristiane de Jesus Nunes dos Santos ${ }^{1}$, Ana Paula Beltran Moschione Castro ${ }^{1}$, \\ Luiz Antônio Nunes de Oliveira², Lisa Suzuki², Andrea Langone Ferme², Magda Maria Sales Carneiro-Sampaio¹, \\ Antonio Carlos Pastorino ${ }^{1}$
}

${ }^{1}$ Unit of Allergy and Immunology, Department of Pediatrics, Instituto da Criança, Hospital das Clínicas, Faculdade de Medicina, Universidade de São Paulo (HC-FMUSP), São Paulo, SP, Brazil ${ }^{2}$ Diagnostic Imaging Service, Instituto da Criança, HC-FMUSP, São Paulo, SP, Brazil

Study conducted at Unidade de Alergia e Imunologia, Departamento de Pediatria, and at Departamento de Radiologia, Instituto da Criança, Hospital das Clínicas, Faculdade de Medicina, Universidade de São Paulo (HC-FMUSP), São Paulo, SP, Brazil

Article received: 6/29/2016 Accepted for publication: 7/26/2016

*Correspondence: Departamento de Pediatria Address: Av. Dr. Enéas de Carvalho Aguiar, 647 São Paulo, SP - Brazil Postal code: 05403-000 mayradorna@uol.com.br

http://dx.doi.org/10.1590/1806-9282.62.06.530

\section{SUMmARY}

Objective: To describe clinical features, tomographic findings and pulmonary function in pediatric patients with primary hypogammaglobulinemia $(\mathrm{PH})$. Method: A retrospective cohort study of children with $\mathrm{PH}$ who received intravenous immunoglobulin (IVIG) and prophylactic antibiotics between 2005 and 2010. Epidemiological and clinical features, computed tomography (CT) findings, and spirometric data were compared, assuming a 5\% significance level.

Results: We evaluated 30 patients with PH. After the start of IVIG replacement, there was a decline in the frequency of pneumonia $(\mathrm{p}<0.001)$. The 11 patients with bronchiectasis in their first CT scan were older at diagnosis $(\mathrm{p}=0.001)$ and had greater diagnostic delay $(\mathrm{p}=0.001)$ compared to patients without bronchiectasis. At the end of the study, 18 patients had bronchiectasis and 27 also had other lung disorders, alone or in combination. The Bhalla score was applied to the last CT scan of 16 patients, with a median score of 11 (range 7-21), with a positive correlation between the score and the number of pneumonias after the start of treatment $(\mathrm{r}=0.561 ; \mathrm{p}=0.024)$. The score was also correlated with forced expiratory volume in one second (FEV1) and forced vital capacity (FVC) values in 13/16 patients, with negative correlation to FEV1 previously to bronchodilator $(\mathrm{r}=-0.778 ; \mathrm{p}=0.002)$ and after bronchodilator $(\mathrm{r}=-0.837$; $\mathrm{p}<0.001)$ and $\mathrm{FVC}(\mathrm{r}=-0.773$; $\mathrm{p}=0.002)$.

Conclusion: Pulmonary complications were common in this cohort, despite the decrease in the frequency of pneumonia with treatment. Early investigation of patients with recurrent infections for primary immunodeficiencies can reduce the frequency of these complications. The monitoring of changes in spirometry may indicate the need to carry out radiological investigation.

Keywords: immunodeficiency syndromes, immunoglobulins, bronchiectasis, lung diseases, spirometry.

\section{INTRODUCTION}

Primary hypogammaglobulinemias $(\mathrm{PH})$ are a group of inherited immunodeficiencies, which have in common a deficient production of antibodies. Patients with $\mathrm{PH}$ are more susceptible to bacterial infections, especially those caused by encapsulated agents, and the respiratory tract is the most affected site. ${ }^{1-7}$

Clinically, the most important PHs are: agammaglobulinemia (A), common variable immunodeficiency (CVID) and hyper IgM syndrome (HIGMS), characterized by low serum concentrations of immunoglobulins and that benefit from regular replacement of immunoglobulin, showing a decline in the frequency and severity of infections. ${ }^{8-12}$

Even with proper replacement treatment, both international and national studies revealed the presence of bronchiectasis in patients with $\mathrm{PH},{ }^{5,6,13-15}$ demonstrating that the decline in infections provided by immunoglobulin replacement does not seem to be enough to prevent the occurrence of pulmonary complications. Chronic pulmonary disease, in particular the development of bron- 
chiectasis, is one of the most important complications in the evolution of patients, with direct implications regarding their quality of life and mortality. ${ }^{1,2,14,16-18}$

The determinants for the appearance of pulmonary complications are not well established. Understanding the factors that contribute to the development of these complications is highly important for its prevention. The study of pediatric populations can provide key information about the process, and allows the evaluation of the effect of early intervention.

The aim of this study was to describe the clinical characteristics, CT-scan findings and pulmonary function, especially the presence of bronchiectasis, in a group of pediatric patients with $\mathrm{PH}$ (A, CVID and HIGMS) receiving intravenous immunoglobulin (IVIG) replacement.

\section{Method}

Retrospective cohort study based on data obtained from medical records of patients followed up in the Unit of Allergy and Immunology of Instituto da Criança, HC-FMUSP, between 2005 and 2010.

We included all patients diagnosed with A, CVID or HIGMS according to the criteria of the Pan-American Group for Immunodeficiency/European Society for Immunodeficiencies (PAGID/ESID) ${ }^{19}$ who received prophylactic antibiotics (amoxicillin or trimethoprim-sulfamethoxazole) and regular IVIG replacement. The doses and intervals of immunoglobulin therapy were adjusted to obtain serum IgG concentrations of at least $600 \mathrm{mg} /$ $\mathrm{dL}$ immediately before the next infusion.

\section{Demographic and clinical data}

The clinical features analyzed were: gender, number and type of infections before and after the diagnosis of immunodeficiency, age at onset of symptoms, age at diagnosis, age at start of treatment, and duration of treatment with immunoglobulin replacement. We defined as "diagnostic delay" the time between symptom onset and the age of diagnosis of the immunodeficiency. We considered as severe pneumonia any pulmonary infection requiring intensive care, endotracheal intubation, hospitalization for treatment with intravenous antibiotics for more than 14 days or the presence of empyema.

\section{Radiological data}

Lung imaging studies were performed using computed tomography (CT) of the chest (conventional and high resolution), using axial sections of varying thickness (1.25 to $10 \mathrm{~mm}$ ) evaluated by the service's radiology specialists. Images taken during or less than 3 months after an acute infection were excluded. For the characterization of the tomographic findings, we included the first and last chest CT scan performed by each patient during follow-up. To assess the severity and extent of lung damage, we applied the Bhalla score. ${ }^{20}$ The scale ranges from 0 to 25 , with higher values related to the presence of more structural damage to the lungs. The score was applied to the last chest CT by three different pediatric radiologists who were unaware of the patient's medical progression, and the final result was obtained by consensus.

\section{Evaluation of pulmonary function}

Pulmonary function was assessed by the pulmonary function test laboratory of the service's Unit of Pneumology, using a portable computerized spirometer (Multispiro Creative Biometrics ${ }^{\circledR}$ ), following the recommendations by the 2002 Brazilian Consensus on Spirometry of the Brazilian Society of Pneumology and Tisiology, and by the American Thoracic Society/European Respiratory Society (ATS/ ERS). ${ }^{21,22}$ Forced expiratory volume in one second (FEV1) and forced vital capacity (FVC) compared with the predicted values were used for correlation with the Bhalla score.

\section{Statistical analysis}

Statistical analysis was performed using SPSS 13.0 where nominal variables were tested using Fisher's exact test and continuous variables using nonparametric tests (MannWhitney and Kruskal-Wallis). Spearman coefficient was used to relate the Bhalla score with the other variables. All $\mathrm{p}$-values $<0.05$ were considered statistically significant.

\section{Ethical aspects}

The study fulfilled the ethical requirements of the institution and was approved by the local Research Ethics Committee (protocol number No. 1172/2009).

\section{Results}

Thirty patients ( 21 males) were diagnosed with A ( $\mathrm{n}=14)$, CVID ( $n=9)$ and HIGMS $(n=7)$. Data on gender, age, and the total follow-up time are shown in Table 1, as well as the age of symptoms onset, age at diagnosis, diagnostic delay, and follow-up time after start of treatment. There was no statistically significant difference between patients with agammaglobulinemia, CVID, and HIGMS in relation to these variables except for gender (male predominance), median total follow-up, and median follow-up time after the start of treatment, which were higher in agammaglobulinemia patients $(\mathrm{p}=0.025)$.

Considering that the analyzed groups did not present differences in relation to most findings, comparisons with 
tomographic findings and spirometry were performed based on the total number of patients $(\mathrm{N}=30)$. The median age at onset of symptoms was 8 months (1-96 months) and the median age at diagnosis was 5.8 years $(0.6-14.6$ years). The median diagnostic delay was 4.7 years $(0.2-13$ years). The median patient follow-up time was 9.9 years (1.8-17.5 years) and the median age of patients at the time of the last assessment was 16.7 years (4.6-23.4 years).

The beginning of IVIG treatment occurred just after PID diagnosis in 27 patients. In one patient with HIGMS the delay was 3 months, in other with CVID it was 7 months and in another CVID patient was 3.5 years.

The most common clinical manifestations before diagnosis were upper and lower respiratory tract infections. Pneumonia was the most common clinical manifestation before diagnosis, occurring in 24 patients (80\%). Considering the total number of patients, the median frequency of pneumonia was 0.6 episodes/patient/year (0-12 episodes/patient/year). After the start of IVIG replacement, the frequency of pneumonia was 0.1 episodes/patient/ year (0-1.7 episodes/patient/year), showing a statistically significant reduction $(\mathrm{p}<0.001)$. Before the start of IVIG replacement, severe pneumonia was diagnosed in 12 of 30 patients $(40 \%)$, with three presenting more than one episode, while after the replacement therapy severe pneumonia occurred in 4 of 30 patients (13.3\%), two had one episode and the other two had two episodes each.

All patients underwent at least two chest CT during follow-up and in 11 of them (36\%) bronchiectasis were diagnosed in the first scan. Patients with bronchiectasis were older at diagnosis $(\mathrm{p}=0.001)$ and had greater delay in diagnosis ( $\mathrm{p}=0.001)$ than those without bronchiectasis. There was no statistically significant difference in relation to age of symptoms onset or the frequency of pneumonia before the start of treatment (Table 2). Twelve of the 30 patients underwent the first CT scan at diagnosis and six of them presented bronchiectasis at that time.

During follow-up, other seven patients developed bronchiectasis, the last CT scan being performed with a median of 7.2 years after the start of treatment (0.4-16.7 years variation), and, at the end of data collection, 18 of 30 patients had bronchiectasis. There were no statistically significant differences between patients with and without bronchiectasis at the last CT scan in relation to age of onset, age at diagnosis, delay in diagnosis, treatment duration, frequency of pneumonia or occurrence of severe pneumonia before or after the beginning of treatment (Table 3).

TABLE 1 Comparison of the groups of patients with primary hypogammaglobulinemia regarding demographic, clinical, and treatment data.

\begin{tabular}{|c|c|c|c|c|}
\hline Variable & $A(n=14)$ & CVID $(n=9)$ & HIGMS (n=7) & $\mathbf{p}$ \\
\hline Gender & & & & $0.0001^{\#}$ \\
\hline M & 14 & 2 & 5 & \\
\hline $\mathrm{F}$ & 0 & 7 & 2 & \\
\hline Age (years) & & & & $0.152^{*}$ \\
\hline Median & 16.5 & 18.9 & 13 & \\
\hline$(\min -\max )$ & $(10.7-23.4)$ & $(12-20)$ & $(4.6-19.7)$ & \\
\hline Total follow-up time (years) & & & & $0.025^{*}$ \\
\hline Median & 11.2 & 9.2 & 6.5 & \\
\hline$(\min -\max )$ & $(3.8-17.5)$ & $(4.9-16.5)$ & $(2.7-10.2)$ & \\
\hline Onset of symptoms (months) & & & & $0.746^{*}$ \\
\hline Median & 8 & 10 & 10 & \\
\hline$(\min -\max )$ & $(1-52)$ & $(2-96)$ & $(4-48)$ & \\
\hline Age at diagnosis (months) & & & & $0.078^{*}$ \\
\hline Median & 50 & 108 & 74 & \\
\hline$(\min -\max )$ & $(20-96)$ & $(9-164)$ & $(7-175)$ & \\
\hline Time from onset of symptoms to start of treatment (years) & & & & $0.096^{*}$ \\
\hline Median & 3.3 & 6 & 4.9 & \\
\hline$(\min -\max )$ & $(0.2-6.8)$ & $(0.33-11.1)$ & $(0.3-13)$ & \\
\hline Time of follow-up after the start of treatment (years) & & & & $0.025^{*}$ \\
\hline Median & 11.2 & 8.7 & 6.5 & \\
\hline$(\min -\max )$ & $(3.8-17.5)$ & $(1.8-14.5)$ & $(2.7-10.2)$ & \\
\hline
\end{tabular}

A: agammaglobulinemia; CVID: common variable immunodeficiency; HIGMS: hyper IgM syndrome. "Fisher's exact test; ${ }^{*}$ Kruskal-Wallis 
TABLE 2 Factors associated with bronchiectasis in the first chest CT.

Finding

Onset of symptoms (months)

Median

(min-max)

Age at diagnosis (months)

Median

$(\min -\max )$

Diagnostic delay (months)

Median

(min-max)

$\mathrm{PN} /$ patient/year before treatment

Median

(min-max)

Severe PN/patient/year before treatment

Median

$(\min -\max )$

*Mann-Whitney; CT: computed tomography; PN: pneumonia.

\section{Bronchiectasis}

Present

$(n=11)$

11

(2-96)

96

(54-175)

82

(43-156)

0.5

(0.1-3.3)

0.1

(0-0.3) $\mathrm{p}^{*}$

(n=19)

0.718

(1-72)

0.001

42

(7-162)

0.001

35

(2-90)

0.746

0.8

(0-12) (0-4)

\section{TABLE 3 Comparison of the 30 patients for the presence of bronchiectasis $(B C T)$ at the final evaluation.}

Finding

Bronchiectasis

Present

$(n=18)$

Absent

$\mathbf{P}^{*}$

Age at onset of symptoms (months)

9

8

Median

(1-96)

$(1-72)$

Age at diagnosis (months)

44

Median

80.5

44

(min-max)

(9-175)

(7-162)

Time from onset of symptoms to start of treatment (years)

Median

69

40.5

(min-max)

(2-156)

(3-90)

$\mathrm{PN} /$ year before treatment

Median

0.5

0.75

(min-max)

(0-12)

$(0-12)$

PN/year after treatment

Median

0.1

(min-max)

$(0-1.7)$

Severe PN/year before treatment

Median

0

(min-max)

$(0-0.3)$

Severe PN/year after treatment

(min-max)

$(0-0.3)$

Time of follow-up after the start of treatment (years)

Median

(min-max)

PN: pneumonia; *Mann-Whitney
10.2

$(2.7-16.8)$
0

$(0-4)$

$(0-0.1)$

6.8

$(1.8-17.5)$ 
In addition to bronchiectasis, $90 \%$ (27/30) of patients had other findings, alone or combined, at the last CT scan: bronchial wall thickening $(n=16)$, air trapping $(n=12)$, atelectasis $(n=9)$, mucus plug $(n=4)$, calcified nodules $(\mathrm{n}=3)$, bubbles $(\mathrm{n}=1)$.

The application of the Bhalla score was possible in the last CT scan in only 16 patients. These scans were performed with a median of 7.7 years after the start of IVIG replacement (variation of 1.2-16.4 years). The median score was 11 (range 7-21). Thirteen of 16 patients underwent spirometry in the same year of the last CT scan. These results were correlated with Bhalla score. A statistically significant correlation was found between the score of CT and pre-bronchodilator FEV1 ( $\mathrm{r}=-0.778$; $\mathrm{p}=0.002)$, post-bronchodilator FEV1 $(\mathrm{r}=-0.837$; $\mathrm{p}<0.001)$ and FVC $\left(r=-0.773 ; p^{=0.002}\right)$. A positive correlation between Bhalla score and the number of pneumonias after the start of treatment has been identified in these 16 patients ( $\mathrm{r}=0.561$; $\mathrm{p}=0.024$ ), but no correlation was found between Bhalla score and age at diagnosis, diagnostic delay, number of pneumonias before the start of treatment, and number of severe pneumonia before or after the start of treatment.

\section{Discussion}

The presence of pulmonary complications in patients with primary hypogammaglobulinemia is often reported in the literature, but few Brazilian studies describe the importance of early diagnosis and prompt treatment for these immunodeficiencies to prevent or minimize long-term complications. The importance of our study was to characterize a group of patients with $\mathrm{PH}$, who received prophylactic antibiotics, and could benefit from early and adequate replacement of immunoglobulin. Also, to identify, in patients with pulmonary changes, what could have been done either based on radiological assessment or spirometry that would anticipate potential interventions.

In recent years, IVIG dosing and administration schedules started to be adjusted individually to maintain IgG trough levels of $600 \mathrm{mg} / \mathrm{dL}$ for all patients and above 800 $\mathrm{mg} / \mathrm{dL}$ for patients with bronchiectasis, in addition to the adjustment based on clinical outcomes. More recently, studies have shown that higher concentrations were correlated with better clinical outcomes. ${ }^{23}$ It is important to consider that in our study patients received doses of immunoglobulin for a few years without this individualization, maintaining IgG levels around $500 \mathrm{mg} / \mathrm{dL}$, according to the values recommended by the literature at the time. ${ }^{8}$ The maintenance of lower serum IgG levels may explain the development of bronchiectasis in our patients. However, even some patients diagnosed more recently who had appropriate $\operatorname{IgG}$ concentrations developed this complication, as reported in the literature, suggesting that other factors must be involved. ${ }^{3,24-28}$ In this context, our study investigated possible factors related to the development of pulmonary complications in this cohort.

Pneumonia was the most common clinical manifestation before diagnosis in our study group. Furthermore, our study demonstrated the efficacy of immunoglobulin replacement in reducing the frequency and severity of pneumonia in accordance with other studies of patients with $\mathrm{PH}^{8-12,25,29-32}$

Bronchiectasis was the most frequent tomographic finding in this cohort and its early occurrence was associated with older age at diagnosis and greater diagnostic delay. Plebani et al. ${ }^{3}$ and Basile et al. ${ }^{6}$ have already reported the association between age at diagnosis and the presence of bronchiectasis in patients with agammaglobulinemia, as well as Baris et al., ${ }^{33}$ who reported this association for patients with CVID. These data give support to the importance of early diagnosis in the prevention of comorbidities that may compromise patient's quality of life and survival. Awareness of PID as a cause of severe or recurrent pneumonia and active screening of siblings, and other family members of patients with PID, may allow early diagnosis and even the identification of yet asymptomatic patients. ${ }^{34}$

Chest CT has been used to assess the presence of pulmonary complications and, in the past, routine CT was encouraged as a monitoring method. However, the risk of repeated exposure to radiation demanded an alternative approach. The Bhalla score, ${ }^{13}$ initially proposed for the evaluation of patients with cystic fibrosis, was used to evaluate patients' chest CT due to the absence of a specific score for PID. Subsequently, a tomographic score was developed, but only for patients with CVID. ${ }^{35}$ The correlations between Bhalla score and FEV1 and FVC found in our study were also described by Gharagozlou et al. ${ }^{36}$ This suggests that the results of spirometry, in addition to clinical evaluation, could help monitoring these patients and that lung function changes could be indicators of the necessity of further investigation.

The positive correlation between the Bhalla score and the number of pneumonia episodes after IVIG replacement found in our study reinforces the need to prevent respiratory infections by maintaining high serum IgG trough levels, antimicrobial prophylaxis, and chest physiotherapy.

The study has limitations especially due to its retrospective design, loss of data and heterogeneity regarding immunoglobulin doses used over the years. Prospective and multicenter studies with more patients could be designed in order to control all variables related to pulmo- 
nary complications, allowing risk factors assessment using multivariable analysis.

\section{Conclusion}

In this cohort of patients with primary hypogammaglobulinemia, immunoglobulin replacement combined with the use of prophylactic antibiotics reduced the frequency and severity of lung infections, but did not prevent the development of bronchiectasis and other pulmonary complications.

The association between the development of bronchiectasis and older age at diagnosis as well as diagnostic delay points out the importance of considering the hypothesis of primary immunodeficiency as a differential diagnosis in patients with severe or repeated pneumonia.

Routine pulmonary evaluation is needed for early detection of complications and in this sense, spirometry and clinical evaluation may indicate the need to include imaging methods for detection of morphological abnormalities in the lungs.

\section{ACKNOWLEDGMENTS}

We acknowledge with affection and admiration the participation of Prof. Cristina Miuki Abe Jacob in the planning of our study, and her contributions throughout the work. We also thank Dr. Fabíola Ade Villac for her advice regarding the use of the Bhalla score. We thank Dr. Ulisses Dória Filho for performing the statistical analysis.

\section{Resumo}

Hipogamaglobulinemia primária: o impacto do diagnóstico precoce nas complicações pulmonares

Objetivo: descrever características clínicas, tomográficas e de função pulmonar em pacientes pediátricos com hipogamaglobulinemia primária (HP).

Método: estudo de coorte retrospectivo de crianças com HP que recebiam gamaglobulina endovenosa (GEV) e antibiótico profilático entre 2005 e 2010. As características epidemiológicas, clínicas, os achados de tomografia e espirometria foram comparadas adotando níveis de significância de 5\%.

Resultados: foram avaliados 30 pacientes com HP. Após o início da reposição de GEV, houve redução da frequência de pneumonias $(\mathrm{p}<0,001)$. Os 11 pacientes que apresentavam bronquiectasias na primeira tomografia computadorizada (TC) eram mais velhos ao diagnóstico $(\mathrm{p}=0,001)$ e tiveram maior atraso no diagnóstico $(\mathrm{p}=0,001)$ quando comparados aos pacientes sem bronquiectasias. Ao final do estudo, 18 pacientes apresentavam bronquiectasias e 27/30 também apresentaram outras alterações pulmonares, isoladas ou concomitantes. O escore de Bhalla foi aplicado à última TC de 16/30 pacientes, com mediana do escore de 11 (variação 7-21), com correlação positiva entre o escore e o número de pneumonias após o início do tratamento ( $\mathrm{r}=0,561 ; \mathrm{p}=0,024)$. O escore foi ainda correlacionado com valores de volume expiratório forçado no primeiro segundo (VEF1) e capacidade vital forçada (CVF) obtidos por espirometria de 13/16 pacientes, com correlação negativa com VEF1 pré- $(r=-0,778 ; p=0,002)$ e pós-broncodilatador $(\mathrm{r}=-0,837 ; \mathrm{p}<0,001)$ e CVF $(\mathrm{r}=-0,773 ; \mathrm{p}=0,002)$.

Conclusão: complicações pulmonares foram frequentes nesta coorte, apesar da diminuição na frequência de pneumonias com o tratamento. A investigação precoce de pacientes com infecções de repetição para imunodeficiências primárias pode reduzir a frequência dessas complicações. A monitorização de alterações na espirometria pode indicar a necessidade de investigação radiológica.

Palavras-chave: síndromes de imunodeficiência, imunoglobulinas, bronquiectasia, pneumopatias, espirometria.

\section{References}

1. Lederman HM, Wilkenstein JA. X-linked agammaglobulinemia: an analysis of 96 patients. Medicine (Baltimore). 1985; 64(3):145-56.

2. Cunningham-Rundles $\mathrm{C}$, Bodian C. Common variable immunodeficiency: clinical and immunological features of 248 patients. Clin Immunol. 1999; 92(1):34-48.

3. Plebani A, Soresina A, Rondelli R, Amato GM, Azzari C, Cardinale F, Cazzola G, et al.; Italian Pediatric Group for XLA-AIEOP. Clinical, immunological, and molecular analysis in a large cohort of patients with X-linked agammaglobulinemia: an Italian multicenter study. Clin Immunol. 2002; 104(3):221-30.

4. Winkelstein JA, Marino MC, Ochs H, Fuleihan R, Scholl PR, Geha R, et al. The X-linked hyper-IgM syndrome: clinical and immunologic features of 79 patients. Medicine (Baltimore). 2003; 82(6):373-84.

5. Winkelstein JA, Marino MC, Lederman HM, Jones SM, Sullivan K, Burks AW, et al. X-linked agammaglobulinemia: report on a United States registry of 201 patients. Medicine (Baltimore). 2006; 85(4):193-202.

6. Basile N, Daniela S, Oleastro M, Rosenweig S, Prieto E, Rossi J, et al. Clinical and molecular analysis of 49 patients with X-linked agammaglobulinemia from a single center in Argentina. J Clin Immunol. 2009; 29(1):123-9.

7. Chan HY, Yang YSH, Yu HH, Chien YH, Chiang LL, Chiang BL. Clinical characteristics and outcome of primary antibody deficiency: a 20-year followup study. J Formos Med Assoc. 2014; 113(6):340-8.

8. Roifman CM, Levison $\mathrm{H}$, Gelfand EW. High-dose versus low-dose intravenous immunoglobulin in hypogammaglobulinaemia and chronic lung disease. Lancet. 1987; 1(8541):1075-7.

9. Skull S, Kemp A. Treatment of hypogammaglobulinaemia with intravenous immunoglobulin, 1973-93. Arch Dis Child. 1996; 74(6):527-30.

10. Aghamohammadi A, Moin M, Farhoudi A, Rezaei N, Pourpak Z, Movahedi $\mathrm{M}$, et al. Efficacy of intravenous immunoglobulin on the prevention of pneumonia in patients with agammaglobulinemia. FEMS Immunol Med Microbiol. 2004; 40(2):113-8.

11. Quartier P, Bustamante J, Sanal O, Plebani A, Debré M, Deville A, et al Clinical, immunologic and genetic analysis of 29 patients with autosomal recessive hyper-IgM syndrome due to Activation-Induced Cytidine Deaminase deficiency. Clin Immunol. 2004; 110(1):22-9.

12. Pourpak Z, Aghamohammadi A, Sedighipour L, Farhoudi A, Movahedi $\mathrm{M}$, Gharagozlou M, et al. Effect of regular intravenous immunoglobulin 
therapy on prevention of pneumonia in patients with common variable immunodeficiency. J Microbiol Immunol Infect. 2006; 39(2):114-20.

13. Hausser C, Virelizier JL, Buriot D, Griscelli C. Common variable hypogammaglobulinemia in children. Clinical and immunologic observations in 30 patients. Am J Dis Child. 1983; 137(9):833-7.

14. Aghamohammadi A, Pouladi N, Parvaneh N, Yeganeh M, Movahedi M, Gharagolou M, et al. Mortality and morbidity in common variable immunodeficiency. J Trop Pediatr. 2007; 53(1):32-8.

15. Costa-Carvalho BT, Wandalsen GF, Pulici G, Aranda CS, Solé D. Pulmonary complications in patients with antibody deficiency. Allergol Immunopathol (Madr). 2011; 39(3):128-32.

16. Thickett KM, Kumararatne DS, Banerjee AK, Dudley R, Stableforth DE. Common variable immune deficiency: respiratory manifestations, pulmonary function and high-resolution CT scan findings. QJM. 2002; 95(10):655-62.

17. Howard V, Greene JM, Pahwa S, Wilkenstein JA, Boyle JM, Kocaf M, et al. The health status and quality of life of adults with X-linked agammaglobulinemia. Clin Immunol. 2006; 118(2-3):201-8.

18. Chapel H, Lucas M, Lee M, Bjorkander J, Webster D, Grimbacher B, et al Common variable immunodeficiency disorders: division into distinct clinical phenotypes. Blood. 2008; 112(2):277-86.

19. Conley ME, Notarangelo LD, Etzioni A. Diagnostic criteria for primary immunodeficiencies. Representing PAGID (Pan-American Group for Immunodeficiency) and ESID (European Society for Immunodeficiencies). Clin Immunol. 1999; 93(3):190-7.

20. Bhalla M, Turcios N, Aponte V, Jenkins M, Leitman BS, McCauley DI, et al. Cystic fibrosis: scoring system with thin-section CT. Radiology. 1991; 179(3):783-8.

21. Sociedade Brasileira de Pneumologia e Tisiologia (SBPT): Diretrizes para Testes de Função Pulmonar. J Pneumol. 2002; 28(3):S1-S238.

22. Miller MR, Hankinson J, Brusasco V, Burgos F, Casaburi R, Coates A, et al.; ATS/ERS Task Force. Standardisation of spirometry. Eur Respir J. 2005; 26(2):319-38.

23. Orange JS, Grossman WJ, Navickis RJ, Wilkes MM. Impact of trough IgG on pneumonia incidence in primary immunodeficiency: a meta-analysis of clinical studies. Clin Immunol. 2010; 137:21-30.

24. Kainulainen L, Varpula M, Liippo K, Svedström E, Nikoskelainen J, Ruuskanen O. Pulmonary abnormalities in patients with primary hypogammaglobulinemia. J Allergy Clin Immunol. 1999; 104(5):1031-6.

25. Quinti I, Soresina A, Spadaro G, Martino S, Donnanno S, Agostini C, et al.; Italian Primary Immunodeficiency Network. Long-term follow-up and outcome of a large cohort of patients with common variable immunodeficiency. J Clin Immunol. 2007; 27(3):308-16

26. Oksenhendler E, Gérard L, Fieschi C, Malphettes M, Mouillot G, Jaussaud $\mathrm{R}$, et al.; DEFI Study Group. Infections in 252 patients with common variable immunodeficiency. Clin Infect Dis. 2008; 46(10):1547-54

27. Ardeniz O, Başoğlu OK, Günşar F, Unsel M, Bayraktaroğlu S, Mete N, et al Clinical and immunological analysis of 23 adult patients with common variable immunodeficiency. J Investig Allergol Clin Immunol. 2010; 20(3):222-36.

28. Quinti I, Soresina A, Guerra A, Rondelli R, Spadaro G, Agostini C, et al.; IPINet Investigators. Effectiveness of immunoglobulin replacement therapy on clinical outcome in patients with primary antibody deficiencies: results from a multicenter prospective cohort study. J Clin Immunol. 2011; 31(3):315-22.

29. Maarschalk-Ellerbroek LJ, Hoepelman AI, van Montfrans JM, Ellerbroek PM. The spectrum of disease manifestations in patients with common variable immunodeficiency disorders and partial antibody deficiency in a university hospital. J Clin Immunol. 2012; 32(5):907-21.

30. Aghamohammadi A, Farhoudi A, Moin M, Rezaei N, Kouhi A, Pourpak Z, et al. Clinical and immunological features of 65 Iranian patients with common variable immunodeficiency. Clin Diagn Lab Immunol. 2005; 12(7):825-32.

31. Quartier P, Debré M, De Blic J, de Sauverzac R, Sayegh N, Jabado N, et al Early and prolonged intravenous immunoglobulin replacement therapy in childhood agammaglobulinemia: a retrospective survey of 31 patients. J Pediatr. 1999; 134(5):589-96.

32. Martínez García MA, de Rojas MD, Nauffal Manzur MD, Muñoz Pamplona MP, Compte Torrero L, Macián V, et al. Respiratory disorders in common variable immunodeficiency. Respir Med. 2001; 95(3):191-5.

33. Baris S, Ercan H, Cagan HH, Ozen A, Karakoc-Aydiner E, Ozdemir C, et al. Efficacy of intravenous immunoglobulin treatment in children with common variable immunodeficiency. J Investig Allergol Clin Immunol. 2011;21(7):514-21.

34. Arkwright PD, Gennery AR. Ten warning signs of primary immunodeficiency: a new paradigm is needed for the 21st century. Ann N Y Acad Sci. 2011; 1238:7-14

35. van de Ven AA, van Montfrans JM, Terheggen-Lagro SW, Beek FJ, Hoytema van Konijnenburg DP, Kessels OA, et al. A CT scan score for the assessment of lung disease in children with common variable immunodeficiency disorders. Chest. 2010; 138(2):371-9.

36. Gharagozlou M, Ebrahimi FA, Farhoudi A, Aghamohammadi A, Bemanian $\mathrm{MH}, \mathrm{zChavoshzadeh} \mathrm{Z}$, et al. Pulmonary complications in primary hypogammaglobulinemia: a survey by high resolution CT scan. Monaldi Arch Chest Dis. 2006; 65(2):69-74 